\title{
Tracheal rhinoscleroma treated by argon laser
}

\author{
ISOBEL WILLIAMS, GRANT RADCLIFFE, MARTIN HETZEL, JOHN MILLARD \\ From the Department of Thoracic Medicine, St James's Hospital, London
}

Rhinoscleroma is a chronic progressive granulomatous condition due to Klebsiella rhinoscleromatis. ${ }^{\prime}$ In severe cases the typical nodular lesions may extend from the nasopharynx into the respiratory tract and be refractory to antibiotics. We are currently investigating the use of laser treatment for lesions in the trachea and major bronchi. ${ }^{2}$ Such treatment is applicable to benign and malignant lesions, and this report illustrates the response obtained in a man presenting with severe dyspnoea due to rhinoscleroma of the trachea.

\section{Case report}

A 23-year-old Egyptian man presented to Charing Cross Hospital in 1977 complaining of nasal obstruction, frontal headaches, a hoarse voice, and breathlessness. The diagnosis of rhinoscleroma was confirmed by biopsy and the patient initially responded to antibiotics. Subsequently, however, he required multiple excisions and cryotherapy of granulomatous lesions from the upper respiratory tract, larynx, and subglottic area.

In 1981 he complained of increasing dyspnoea. Bronchoscopy showed multiple tracheal lesions throughout the trachea and extending to the orifices of the main bronchi, which reduced the lumen to a slit. Further treatment with antibiotics did not relieve the dyspnoea, and attempts to

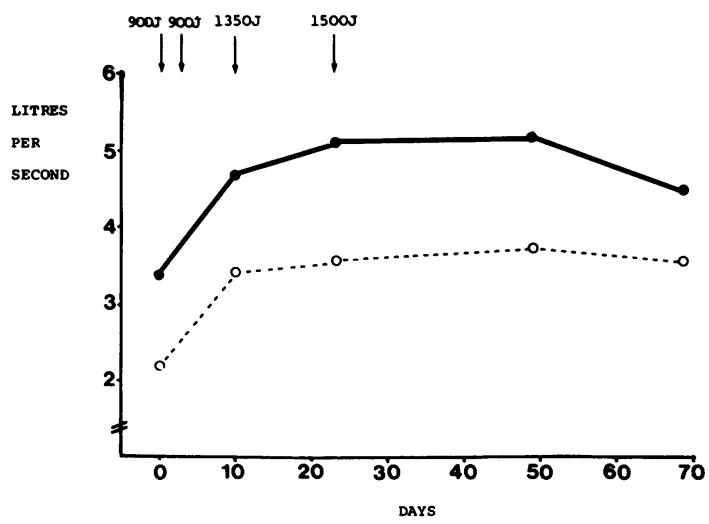

Peak flow rate and forced expiratory volume in one second measured serially during and after the course of laser treatment (arrows). Solid line: peak expiratory flow rate; dotted line: $F E V_{1}$.

Address for reprint requests: Dr John Millard, Department of Thoracic Medicine, St James's Hospital, London SW12 8HW. core out the lesions surgically were impeded by excessive bleeding. No further conventional treatment was possible. He was referred for a trial of laser treatment at St James's Hospital, Balham. This was performed under local anaesthetic by argon laser via a quartz fibre (Quartz Celice, France) passed through the suction channel of a fibreoptic bronchoscope (Olympus B3) ${ }^{3}$ and started in March 1981. He was treated with two treatments of $900 \mathrm{~J}$ and a further two treatments of $1300-1500 \mathrm{~J}$. The lesions burnt away easily and the patient experienced no distress at the procedure. Respiratory function improved after two treatments (fig). After four treatments the peak flow had risen from 3.4 to 5.2 litres per second (from 204 to $3121 / \mathrm{min}$ ) and the forced expiratory volume in one second (FEV $)$ from 2.2 to $3.75 \mathrm{l}$. This improvement has been maintained for five months. There was a concomitant subjective improvement in dyspnoea and exercise tolerance.

\section{Discussion}

Rhinoscleroma is a chronic progressive granulomatous condition first described in $1870 .{ }^{4}$ It affects the nose and may spread to the pharynx, larynx, trachea, and major bronchi. The condition is rare in Britain but endemic in Eastern Europe, including Hungary, Poland, and the Ukraine; it also occurs in Egypt, north and central Africa, Pakistan, Indonesia, and central America.

The disease is associated with $K$ rhinoscleromatis. This organism is found in the cytoplasm of large macrophages (Mikulicz cells) in the subepithelial tissues and some cases respond to treatment with antibiotics-for example, streptomycin and terramycin. Attempts to reproduce the disease experimentally, however, have given conflicting results and it is not certain whether the organism is the sole cause of the condition. Secondary infection is common, and in addition to blockage of the airways patients may complain of purulent nasal discharge and-if the condition spreads beyond the nose- of cough and sputum.

Early results suggest that laser treatment via the fibreoptic bonchoscope can be effective palliative treatment for carcinoma of the trachea and major bronchi. ${ }^{25}$ The principal advantages of this form of treatment are, firstly, the minimal disturbance to the patient, treatment being given under local anaesthetic and so causing little more disturbance than routine fibreoptic bronchoscopy; secondly, the fact that there is no dose limit either in a given session or cumulatively; and, thirdly, the possibility of giving the treatment after other methods have failed. The technique would appear to be equally valuable in non-malignant conditions of major airways, particularly those causing bleeding.

The authors would like to express their thanks to $\mathrm{Mr} \mathrm{H}$ Holden, who referred the patient for laser treatment. 


\section{References}

' Freidmann I, Osborn DA. Systemic pathology. Vol 1. Edinburgh: Churchill Livingstone, 1976:191-235.

${ }^{2}$ Millard FJC, Hetzel M, Williams IP, Bridges C. Endoscopic argon laser treatment of bronchial carcinoma: results. Thorax 1981;36:235.

${ }^{3}$ Hetzel M, Millard FJC, Bridges C, Williams IP. Endos- copic argon laser treatment of bronchial carcinoma: techniques. Thorax 1981;36:235.

4 Hebra F. Ueber ein eigenthümliches Neugebilde an der Nase. Wien Med Wochenschr 1870;20:1-3.

${ }^{5}$ Toty L, Personne C, Colchen A, Vourc'h G. Bronchoscopic management of tracheal lesions using the neodynium yttrium aluminium garnet laser. Thorax 1981;36:175-9. 